\title{
Effects of anabolic steroid use on myocardial perfusion in body-builders: a quantitative cardiovascular magnetic resonance Study
}

\author{
Tevfik F Ismail ${ }^{1 *}$, Li-Yueh Hsu², Peter J Angell ${ }^{3}$, Andrew Jabbour ${ }^{1}$, Anders M Greve², Carla Gonçalves', \\ Ankur Gulati', Benjamin Hewins ${ }^{1}$, Gillian Smith ${ }^{1}$, Rick Wage ${ }^{1}$, Annette L Dahl' ${ }^{1}$, Michael Roughton ${ }^{1}$, Gregory Whyte ${ }^{3}$ \\ , Keith George ${ }^{3}$, Dudley J Pennell ${ }^{1}$, Andrew E Arai ${ }^{2}$, Sanjay K Prasad ${ }^{1}$
}

From 16th Annual SCMR Scientific Sessions

San Francisco, CA, USA. 31 January - 3 February 2013

\section{Background}

Anabolic steroids are known to induce left ventricular hypertrophy (LVH). The pathologic LVH due to hypertrophic cardiomyopathy, hypertension, and aortic stenosis has been associated with myocardial perfusion abnormalities. However, the effects of anabolic steroid misuse on myocardial blood flow (MBF) are unknown.

\section{Methods \\ Twenty one body-builders were studied - 14 anabolic steroid users and 7 controls matched for age and training history. First pass CMR perfusion imaging was performed on a $1.5 \mathrm{~T}$ Avanto (Siemens, Erlangen, Germany) after adenosine-induced hyperemia $(140 \mathrm{mcg} / \mathrm{kg} / \mathrm{min})$ and at rest using a hybrid echo-planar imaging sequence. Images of the base, mid-ventricle and apex were acquired and the myocardium was divided into 16 segments as well as endocardial and epicardial layers. After image registration, a modified Fermi-constrained deconvolution algorithm was applied pixel-wise to quantify absolute MBF. Late gadolinium enhancement (LGE) imaging was performed as well as standard assessment of ventricular volumes, function and LV mass. Data were analysed using a linear mixed effects model.}

\section{Results}

Anabolic steroid-using subjects had significant LVH both in terms of maximum wall thickness and indexed LV mass (Table 1). For the whole cohort, endocardial MBF

${ }^{1}$ CMR Unit \& NHLI Imperial College London, Royal Brompton Hospital \& NHLI Imperial College London, London, UK

Full list of author information is available at the end of the article $(\mathrm{ml} / 100 \mathrm{~g} / \mathrm{min})$ was significantly higher than epicardial MBF at rest $(103 \pm 29.6$ vs $94.5 \pm 26.76, p<0.001)$ but was similar with stress $(235 \pm 64.8$ vs $238 \pm 61.8, \mathrm{p}=0.363)$. The difference in resting epicardial versus endocardial resting MBF $(\beta=-13.5,95 \% \mathrm{CI}:-17.5$ to $-9.44, \mathrm{p}<0.001)$ was greater with steroid use $(\beta=-23.0,95 \% \mathrm{CI}$ : -40.4 to $-5.55, \mathrm{p}=0.010)$ than non-use. However, there was also a significant interaction effect with steroid use and the layer examined such that the difference in endocardial MBF between the steroid users and non-users, and the differences between the groups in epicardial MBF was $6.89 \mathrm{ml} / 100 \mathrm{~g} / \mathrm{min}$ higher ( $95 \% \mathrm{CI}: 1.93$ to $11.8, \mathrm{p}=0.006$ ). Resting differences in MBF due to steroid use persisted after adjusting for wall thickness $(\beta=1.84,95 \%$ CI 0.43 to $3.26, p=0.011$ for wall thickness) but were abolished by vasodilator stress. There was no significant difference in myocardial perfusion reserve index (MPI=stress MBF/ rest $\mathrm{MBF}$ ) between the two groups (steroid MPI: $2.49 \pm$ 0.75 vs non-users: $2.45 \pm 0.57, \mathrm{p}=0.822$ ).

\section{Conclusions}

Hyperemic MBF was similar in strength-trained bodybuilders using anabolic steroids compared with nonusers. However, steroid use appeared to exacerbate resting differences in the transmural distribution of perfusion independent of the effects of wall thickness. Further work is required to delineate the mechanisms responsible for these differences in microvascular function.

\section{Funding}

This work is supported by the NIHR Cardiovascular Biomedical Research Unit at the Royal Brompton and Harefield NHS Foundation Trust, and Imperial College. 
Table 1

\begin{tabular}{|c|c|c|c|c|}
\hline Characteristic - n (\%) & Non-users (mean $\pm S D, n=7$ ) & Steroid users (mean $\pm S D, n=14$ ) & All patients (mean $\pm S D, n=21$ ) & $P$ value \\
\hline Age - years & $29.4(6.4)$ & $29.9(5.1)$ & $29.7(5.4)$ & 0.841 \\
\hline Male - n (\%) & $7(100)$ & $13(92.9)$ & $20(95.2)$ & 0.469 \\
\hline Rest HR $-\min ^{-1}$ & $57.9(4.4)$ & $67.0(10.8)$ & $64.0(10.1)$ & 0.047 \\
\hline Stress HR - $\min ^{-1}$ & $88.2(10.3)$ & $92.4(13.9)$ & $91.1(12.8)$ & 0.516 \\
\hline Rest mean BP - mmHg & $87.0(14.0)$ & $92.3(13.5)$ & $90.6(13.5)$ & 0.415 \\
\hline Stress mean BP - mmHg & $87.4(12.1)$ & $96.8(17.9)$ & $94.0(16.6)$ & 0.256 \\
\hline LV-EDV index $-\mathrm{ml} / \mathrm{m}^{2}$ & $91.3(9.9)$ & $95.5(13.0)$ & $94.1(12.0)$ & 0.466 \\
\hline LV-ESV index $-\mathrm{ml} / \mathrm{m}^{2}$ & $34.3(5.7)$ & $37.5(6.9)$ & $36.5(6.9)$ & 0.306 \\
\hline LV ejection fraction - \% & $62.4(3.6)$ & $61.1(2.7)$ & $61.5(2.7)$ & 0.343 \\
\hline LV mass index $-\mathrm{g} / \mathrm{m}^{2}$ & $79.5(13.4)$ & $101.8(14.4)$ & $94.4(17.5)$ & 0.003 \\
\hline Max wall thickness & $9.6(1.3)$ & $13.2(2.1)$ & $12.0(2.5)$ & $<0.001$ \\
\hline Late gadolinium enhancement & $0(0)$ & $0(0)$ & $0(100)$ & - \\
\hline
\end{tabular}

HR=Heart Rate; BP=Blood Pressure; LV-EDV=Left Ventricular End-diastolic volume; LV-ESV=Left Ventricular End-systolic volume; LV=Left Ventricular.

Dr Ismail is supported by the British Heart Foundation. Dr Arai and Dr Hsu are supported by the National Institutes of Health.

\section{Author details}

${ }^{1}$ CMR Unit \& NHLI Imperial College London, Royal Brompton Hospital \& NHLI Imperial College London, London, UK. ${ }^{2}$ Laboratory of Cardiac Energetics, National Institutes of Health, Bethesda, MD, USA. ${ }^{3}$ Research Institute for Sport and Exercise Sciences, Liverpool John Moore's University, Liverpool, UK.

Published: 30 January 2013

doi:10.1186/1532-429X-15-S1-P145

Cite this article as: Ismail et al:: Effects of anabolic steroid use on myocardial perfusion in body-builders: a quantitative cardiovascular magnetic resonance Study. Journal of Cardiovascular Magnetic Resonance 2013 15(Suppl 1):P145
Submit your next manuscript to BioMed Central and take full advantage of:

- Convenient online submission

- Thorough peer review

- No space constraints or color figure charges

- Immediate publication on acceptance

- Inclusion in PubMed, CAS, Scopus and Google Scholar

- Research which is freely available for redistribution

Submit your manuscript at www.biomedcentral.com/submit
C Biomed Central 